\title{
HPIP: a predictor of lymph node metastasis and poor survival in cervical cancer
}

This article was published in the following Dove Press journal:

OncoTargets and Therapy

26 August 2017

Number of times this article has been viewed

\section{Shan Cao \\ Jingxia Sun \\ Shuai Lin \\ Lu Zhao \\ DiWu \\ Tian Liang \\ Wenji Sheng}

Department of Gynecology and

Obstetrics, The First Affiliated

Hospital of Harbin Medical University,

Harbin, People's Republic of China
Correspondence: Shan Cao

Department of Gynecology and

Obstetrics, The First Affiliated Hospital,

Harbin Medical University, 23 Youzheng

Street, Nangang District, Harbin I5000I,

People's Republic of China

Tel +8645 I 85555920

Email caoshan8I4@I26.com
Background: The aim of this study was to explore the relationships of HPIP expression status with the clinicopathological variables and survival outcomes of patients with cervical cancer (CC).

Methods: We compared the HPIP expression of 119 samples from CC tissues, 20 from cervical intraepithelial tissues, and 20 from normal cervical tissues by using immunohistochemical staining.

Results: It was observed that the ratio of elevated HPIP expression was higher in CC tissues than in cervical intraepithelial neoplasia $(P=0.017)$ and normal cervical tissues $(P=0.001)$. In addition, there was an association between HPIP and clinicopathological factors, such as histological grade $(P<0.001)$, stromal infiltration $(P=0.015)$, lymph node metastasis $(P<0.001)$, lymphovascular space invasion (LVSI; $P=0.026)$, and recurrence $(P=0.029)$. Furthermore, multivariate Cox regression analysis revealed that high HPIP expression ( $P=0.027$ and $P=0.042$ ) as well as the International Federation of Gynaecology and Obstetrics stage ( $P=0.003$ and $P=0.009)$, lymph node metastasis $(P=0.031$ and $P=0.017)$, and LVSI ( $P=0.024$ and $P=0.046)$ were independent prognostic factors. In addition, we demonstrated that high HPIP expression $(P=0.003)$ and LVSI $(P<0.001)$ were independently related to lymph node metastasis.

Conclusion: Elevated HPIP expression may contribute to the progression and metastasis of $\mathrm{CC}$ and may also serve as a new biomarker to predict the prognosis of CC.

Keywords: HPIP, cervical cancer, metastasis, progression, prognosis

\section{Introduction}

Cervical cancer (CC) is the third most common cancer among women worldwide and one of the main causes of cancer-related death in the developing countries. ${ }^{1}$ It continues to be a major public health problem, despite its decreasing incidence and mortality in many countries associated with the wide implementation of Pap smear screening programs in recent years. ${ }^{1,2}$ Most patients with $\mathrm{CC}$ receive standard radiotherapy or chemotherapy or are recommended surgery, with consequent disease remission, yet many patients also relapse and die as a result of tumor progression. Furthermore, the motility and invasiveness of cancer cells play a key role in the mortality of patients with $\mathrm{CC} .{ }^{2,3}$ In addition, clinical outcomes vary significantly between patients and can be difficult to predict. Therefore, the characterization of tumor-specific markers may play an important role in understanding the molecular pathogenesis as well as the prognosis of CC.

HPIP, a nucleocytoplasmic shuttling protein, ${ }^{4}$ was originally isolated based on a yeast two-hybrid screen using a human hematopoietic cDNA-based library. ${ }^{5}$ HPIP has been 
reported to be upregulated in human cancers, ${ }^{4,6-14}$ and several studies suggest that the abnormal expression of HPIP plays an important role in tumor cancer proliferation, cell cycle, adhesion, migration, metastasis, and apoptosis., ${ }^{4-9,12,13,15-17}$ However, the significance of HPIP expression in CC in terms of survival status has not been examined.

In order to explore these, we first conducted the immunohistochemical (IHC) study on HPIP with 119 tumor, 20 normal cervical, and 20 cervical intraepithelial specimens. Subsequently, we correlated the IHC results with clinicopathological factors, including survival status, lymph node metastasis, lymphovascular space invasion (LVSI), and recurrence.

\section{Materials and methods \\ Patients and clinical samples}

This study used archived material from the Department of Pathology at the First Affiliated Hospital of Harbin Medical University, including 20 normal cervical tissues, 20 cervical intraepithelial tissues, and 119 CC tissues from January 2008 to December 2010. Cervical tissues were histologically confirmed by two pathologists. The study was approved by the Ethical Committee of Harbin Medical University, Harbin, People's Republic of China. Written informed consent was obtained from all the patients for this study. Patients with $\mathrm{CC}$ received radical hysterectomy and pelvic lymphadenectomy. None of the patients received chemotherapy, immunotherapy, or radiotherapy before surgery. The tumor stages were assessed according to the International Federation of Gynaecology and Obstetrics (FIGO) staging system. ${ }^{18}$ The histological grades were classified according to the World Health Organization criteria. The patients selected in this study were aged from 27 to 70 years (median $=43$ years).

\section{Follow-up}

The clinical and pathological records of all the patients included in the study were reviewed periodically. Examinations were performed every 3-6 months for the first 3 years and every 12 months thereafter during the follow-up period. The clinical records were obtained from the departments providing follow-up care. All the patients were followed up until death or the study closing date (July 31, 2016). Recurrence was either radiologically or histologically confirmed. Overall survival (OS) was defined as the interval from the date of surgery to death due to any cause or to the date of last contact, and disease-free survival (DFS) was defined as the interval from the date of surgery to proven local recurrence or distant metastasis.

\section{IHC staining and evaluation}

The tissue sections were dried at $60^{\circ} \mathrm{C}$ for 3 hours. After deparaffinization and hydration, the slides were washed with PBS for 2 minutes three times. The washed sections were treated with $3 \% \mathrm{H}_{2} \mathrm{O}_{2}$ in the dark for 5-20 minutes. Antigen retrieval was performed in citrate buffer $(\mathrm{pH}=6.0)$. Each section was then treated with 300-500 mL HPIP rabbit polyclonal antibodies (Abcam, Cambridge, MA, USA; at a dilution of $1: 150$ ) solution at $4{ }^{\circ} \mathrm{C}$ overnight. After washing with PBS as before, each section was incubated with 300-500 mL secondary antibody at room temperature for 20 minutes. After washing with PBS, each slide was treated with 3,3-diaminobenzidine tetrahydrochloride (Dako, Produktionsvej, Denmark) and then counterstained with hematoxylin.

HPIP expression was assessed by multiplying the scores of staining reaction and staining intensity. Staining intensity was graded as 0 (no staining), 1 (weak staining = light yellow), 2 (moderate staining = yellow brown), and 3 (strong staining $=$ brown $)$. The percentage $(0 \%-100 \%)$ of the extent of reactivity was scored as follows: $0(<5 \%$ positive cells), 1 (5\%-25\% positive cells), $2(25 \%-50 \%$ positive cells $)$, 3 (51\%-75\% positive cells), and 4 ( $>75 \%$ positive cells). Scores 0-2 were classified as low expression, and the remainders were classified as high expression. ${ }^{11,19}$

Two pathologists without the knowledge of the clinicopathological variables scored the staining on each slide independently. Finally, the staining assessment and the allocation of tumors by the two pathologists were similar. Cases with discrepancies were simultaneously rereviewed by the original two pathologists and a senior pathologist until a consensus was reached.

\section{Statistical analyses}

All the analyses were conducted by using statistical software (SPSS version 16.0, Inc., Chicago, IL, USA). Associations between HPIP expression and clinicopathological variables were assessed by using the $\chi^{2}$ test. The Kaplan-Meier method was used to estimate OS and DFS. The influence of different variables on survival was assessed by using univariate and multivariate Cox regression analyses. Univariate and multivariate logistic regressions were used to assess the association between HPIP expression and lymph node metastasis. The level of significance was set at $P<0.05$. 


\section{Results \\ HPIP expression}

HPIP expression was mainly observed in the cytoplasm of tumor cell and epithelial cells (Figure 1). A total of 64 (53.8\%) patients showed high HPIP expression. The ratio of elevated HPIP expression was higher in CC tissues than in cervical intraepithelial neoplasia $(P=0.017)$ and normal cervical tissues $(P=0.001$; Table 1$)$. However, there were no significant differences between cervical intraepithelial neoplasia and normal cervical tissues $(P=0.429)$.

\section{Association between HPIP expression and clinicopathological features}

We analyzed the associations between HPIP expression levels and a series of clinicopathological characteristics, including age, histological type, histological grade, FIGO stage, depth of stromal infiltration, tumor size, lymph node metastasis, and LVSI in CCs (Table 2). High HPIP expression was significantly associated with lower histological grade $(P<0.001)$, deeper stromal infiltration $(P=0.015)$, metastasis of lymph node $(P<0.001)$, LVSI $(P=0.026)$, and recurrence $(P=0.029)$.

\section{Univariate and multivariate analyses for the prognosis of patients with CC}

Both univariate and multivariate survival analyses were used to evaluate the effects of HPIP expression status and clinicopathological features on prognosis. Figure 2 shows the Kaplan-Meier 5-year OS and DFS curves stratified for HPIP expression status. Univariate analyses (Table 3 ) of OS and DFS identified increased HPIP expression $(P=0.003$ and $P=0.002$ ), lower histological grade $(P=0.011$ and $P=0.008)$, advanced FIGO stage ( $P=0.012$ and $P=0.016)$, deep stromal infiltration ( $P=0.026$ for both), larger tumor size $(P=0.029$ and $P=0.034)$, metastasis of lymph node $(P<0.001$ for both), and LVSI $(P<0.001$ for both) as significant prognostic predictors. Other features had no prognostic value. By using multivariate analysis, we found that FIGO stage ( $P=0.003$ and $P=0.009$ ), lymph node metastasis $(P=0.031$ and $P=0.017)$, LVSI $(P=0.024$ and $P=0.046)$, and high HPIP expression $(P=0.027$ and $P=0.042)$ were independent prognostic factors (Table 4).

\section{Effect of HPIP expression status on lymph node metastasis in CCs}

The univariate analysis of clinicopathological variables for lymph node metastasis was performed. In addition to elevated HPIP expression $(P<0.001)$, the presence of lymph node metastasis was positively associated with lower histological grade $(P=0.025)$, deep stromal infiltration $(P=0.016)$, larger tumor size $(P=0.040)$, and LVSI $(P<0.001)$. Moreover, multivariate logistic regression analysis indicated that high HPIP expression $(P=0.003$; odds ratio $[\mathrm{OR}]=7.746$; $95 \%$ $\mathrm{CI}=2.043-29.365)$ and LVSI $(P<0.001$; OR $=7.416$; $95 \%$ $\mathrm{CI}=2.544-21.620)$ were independently related to lymph node metastasis (Table 5).

\section{Discussion}

Altered expression of HPIP has been observed in various tumor samples and cell lines. In this study, the ratio of increased HPIP expression was higher in CC tissues than in cervical intraepithelial neoplasia and normal cervical tissues.
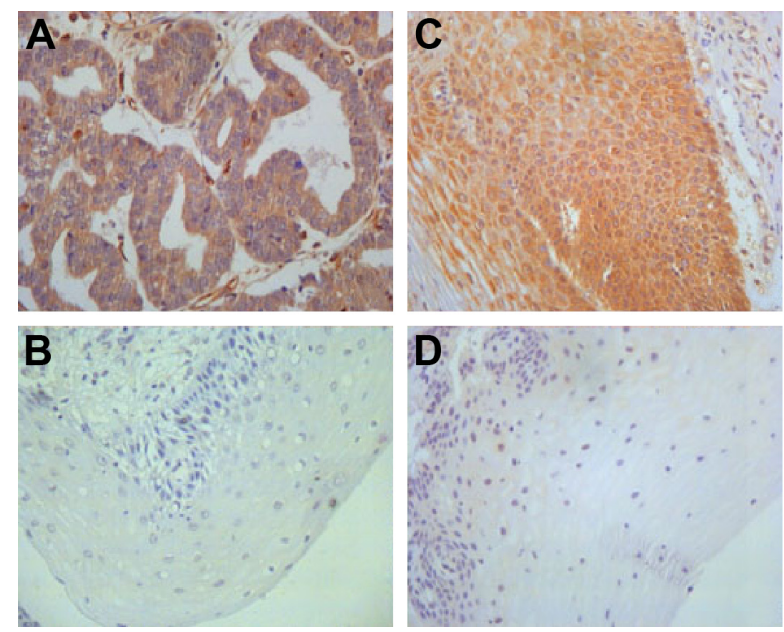
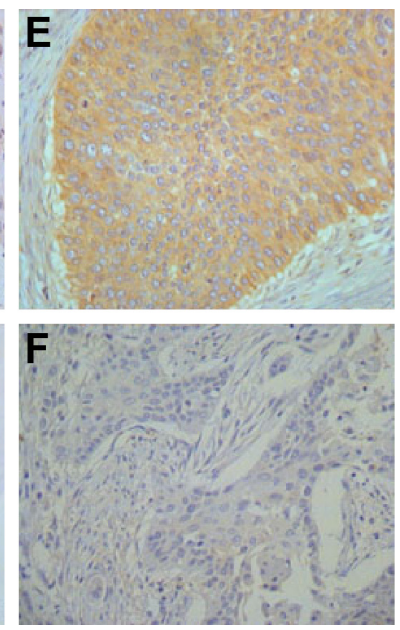
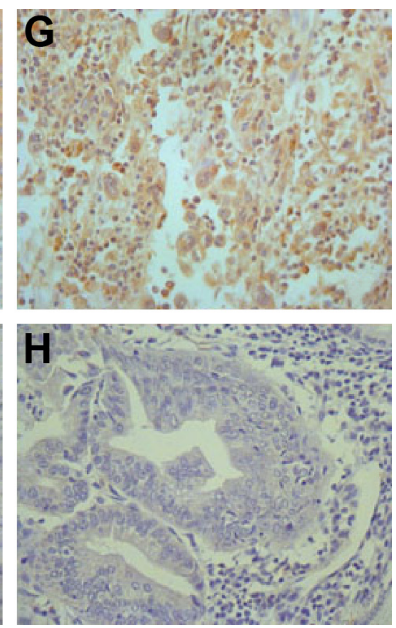

Figure I Immunohistochemical staining of HPIP in cervical tissues $(\times 400)$

Notes: (A) Positive control in ovarian cancer; (B) low HPIP expression in normal cervical tissues; (C) high HPIP expression in cervical intraepithelial neoplasia; (D) low HPIP expression in cervical intraepithelial neoplasia; (E) high HPIP expression in cervical squamous cell carcinoma; (F) low HPIP expression in cervical squamous cell carcinoma; (G) high HPIP expression in cervical adenocarcinoma; and (H) low HPIP expression in cervical adenocarcinoma. 
Table I Expression of HPIP in different cervical tissues

\begin{tabular}{|c|c|c|c|c|}
\hline & \multirow[t]{2}{*}{ Cases } & \multicolumn{2}{|c|}{ HPIP expression status } & \multirow[t]{2}{*}{$P$-value } \\
\hline & & High (\%) & Low (\%) & \\
\hline Normal cervix & 20 & $3(15.0)$ & $17(85.0)$ & $0.00 \mathrm{I}^{\mathrm{a}}$ \\
\hline $\begin{array}{l}\text { Cervical intraepithelial } \\
\text { neoplasia }\end{array}$ & 20 & $5(25.0)$ & $15(75.0)$ & $0.429^{b}$ \\
\hline Cervical cancer & 119 & $64(53.8)$ & $55(46.2)$ & $0.017^{c}$ \\
\hline
\end{tabular}

Notes: ${ }^{a}$ Cervical cancer versus normal cervix, $P=0.00 \mathrm{I}$; ${ }^{b}$ cervical intraepithelial neoplasia versus normal cervix, $P=0.429$; 'cervical cancer versus cervical intraepithelial neoplasia, $P=0.017$.

This is consistent with the results from the studies on gastric cancer and renal cell carcinoma, ${ }^{11,20}$ which demonstrate that HPIP may play a pivotal role in neoplastic progression. Furthermore, we found that elevated HPIP expression was associated with tumor progression, metastasis, recurrence, and unfavorable outcomes. This finding indicates that HPIP may be an independent prognostic factor. To our knowledge,

Table 2 Relationships of HPIP expression status with clinicopathological factors of cervical cancer

\begin{tabular}{|c|c|c|c|c|}
\hline \multirow[t]{2}{*}{ Variables } & \multirow[t]{2}{*}{ Patients } & \multicolumn{2}{|c|}{ HPIP expression } & \multirow[t]{2}{*}{$P$-value } \\
\hline & & Low & High & \\
\hline All cases & 119 & & & \\
\hline Age (years) & & & & 0.921 \\
\hline$<43$ & 59 & 27 & 32 & \\
\hline$\geq 43$ & 60 & 28 & 32 & \\
\hline Histological type & & & & 0.236 \\
\hline SCC & 106 & 51 & 55 & \\
\hline Adenocarcinoma & 13 & 4 & 9 & \\
\hline Histological grade & & & & $<0.001$ \\
\hline GI & 23 & 14 & 9 & \\
\hline $\mathrm{G} 2$ & 65 & 37 & 28 & \\
\hline G3 & 31 & 4 & 27 & \\
\hline FIGO stage & & & & 0.679 \\
\hline 1 & 69 & 33 & 36 & \\
\hline II & 50 & 22 & 28 & \\
\hline \multicolumn{2}{|c|}{ Depth of stromal infiltration } & & & 0.015 \\
\hline$<\mathrm{I} / 2$ & 68 & 38 & 30 & \\
\hline$\geq \mathrm{I} / 2$ & 51 & 17 & 34 & \\
\hline Tumor size $(\mathrm{cm})$ & & & & 0.218 \\
\hline$<4$ & 82 & 41 & 41 & \\
\hline$\geq 4$ & 37 & 14 & 23 & \\
\hline \multicolumn{2}{|c|}{ Lymph node metastasis } & & & $<0.001$ \\
\hline No & 94 & 52 & 42 & \\
\hline Yes & 25 & 3 & 22 & \\
\hline LVSI & & & & 0.026 \\
\hline No & 93 & 48 & 45 & \\
\hline Yes & 26 & 7 & 19 & \\
\hline Recurrence & & & & 0.029 \\
\hline No & 104 & 52 & 52 & \\
\hline Yes & 15 & 3 & 12 & \\
\hline
\end{tabular}

Abbreviations: FIGO, the Federation of Gynecology and Obstetrics; GI, well differentiated; G2, moderately differentiated; G3, poorly differentiated; LVSI, lymphovascular space invasion; SCC, squamous cell carcinoma. this study provides the first detailed demonstration of an association between clinicopathological variables, prognostic significance, and HPIP expression in CC.

In the current study, we analyzed the association between HPIP expression and clinicopathological features in CC. Elevated HPIP expression was significantly correlated with histological grade, stromal infiltration, lymph node metastasis, LVSI, and recurrence. The Kaplan-Meier method and log-rank test data also demonstrated that the patients with high HPIP expression exhibited significantly poor OS and DFS. The multivariate analysis demonstrated that HPIP expression was an independent prognostic factor for both OS and DFS in CC patients. These results suggest that high HPIP expression plays a pivotal role in CC progression and is significantly associated with an independent poor prognostic factor. Our results are consistent with the previous findings on the roles of HPIP in tumor progression in various cancers, including renal cell carcinoma, ${ }^{20}$ breast cancer, ${ }^{4}$ colorectal cancer, ${ }^{12}$ and ovarian cancer. ${ }^{14}$ All these findings suggest an important tumor biological role of HPIP in carcinogenesis and tumor progression.

Although the status of the retroperitoneal lymph nodes is not included in the FIGO staging system, lymph node metastasis is the strongest prognostic factor for early-stage CC (FIGO stage Ib-IIa) and provides important information for determining the treatment approach. ${ }^{21}$ With regard to lymph node metastasis, multivariate logistic regression analysis indicated that high HPIP expression and LVSI were independently related to lymph node metastasis, suggesting a high possibility that patients with high HPIP expression would be diagnosed with lymph node metastasis. It suggested that HPIP led to modulate cancer cell invasion by increasing cell migration in laboratory models. ${ }^{22,23}$ Mai et al $^{20}$ reported that HPIP knockdown suppresses renal tumor growth and metastasis in nude mice through CK1 $\alpha$. Moreover, some data indicate that HPIP can improve cell proliferation or invasion through the involvement in signal transduction pathways, such as the MAPK/ERK pathway ${ }^{12}$ and the PI3KAKT pathway. ${ }^{9,24}$ In breast cancer, HPIP regulates tumor cell adhesion and migration by activating FAK. ${ }^{4}$ These data provide important evidence that elucidates the mechanism by which HPIP expression contributes to carcinogenesis, tumor progression, and metastasis.

In our study, we showed that high HPIP expression was associated with lower histological grade, deeper stromal infiltration, metastasis of lymph node, LVSI, and recurrence. These results are consistent with the results from previous studies. ${ }^{11,14}$ However, there are no significant relationships 
A

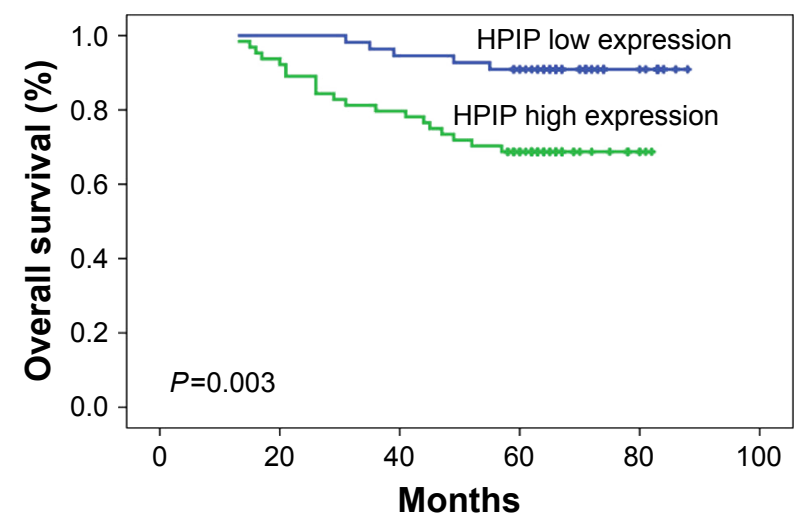

B

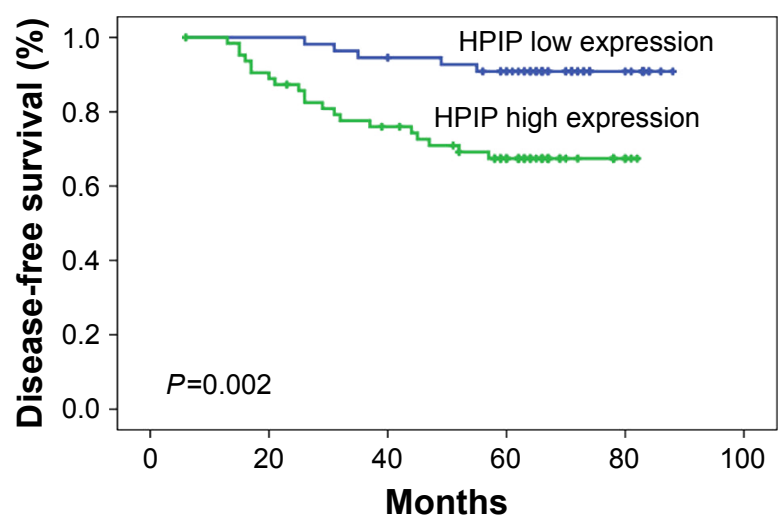

Figure 2 Kaplan-Meier curves for the survival of prognosis in II 9 patients with cervical cancer according to the categories of low and high expressions of HPIP (analyzed with log-rank test).

Notes: (A) Overall survival; (B) disease-free survival.

of HPIP expression either with differentiation or with lymph node metastasis in oral squamous cell carcinoma. ${ }^{8}$ In addition, HPIP expression is correlated with lymph node metastasis instead of differentiation in gastric cancer. ${ }^{11}$ This phenomenon may attribute to the result that HPIP gene plays biological function dependent on different cancer species.

To date, some indicators can explain the mechanisms by which HPIP promotes cancer development. Specifically,

Table 3 Univariate survival analysis of 119 patients with cervical cancer

\begin{tabular}{|c|c|c|c|c|c|c|}
\hline \multirow[t]{2}{*}{ Variables } & \multicolumn{3}{|l|}{ OS } & \multicolumn{3}{|l|}{ DFS } \\
\hline & Mean \pm SD & 5 year $(\%)$ & $P$-value & Mean \pm SD & 5 year $(\%)$ & $P$-value \\
\hline Age (years) & & & 0.973 & & & 0.973 \\
\hline$<43$ & $74.5 \pm 2.8$ & 79.7 & & $74.1 \pm 2.9$ & 79.2 & \\
\hline$\geq 43$ & $76.3 \pm 3.0$ & 78.3 & & $75.1 \pm 3.3$ & 77.7 & \\
\hline Histological type & & & 0.065 & & & 0.072 \\
\hline SCC & $77.2 \pm 2.2$ & 81.1 & & $76.5 \pm 2.3$ & 80.6 & \\
\hline Adenocarcinoma & $58.6 \pm 6.9$ & 61.5 & & $57.9 \pm 7.3$ & 61.5 & \\
\hline Histological grade & & & 0.011 & & & 0.008 \\
\hline GI & $82.3 \pm 2.3$ & 95.7 & & $82.2 \pm 2.4$ & 95.5 & \\
\hline G2 & $76.9 \pm 2.5$ & 81.5 & & $76.5 \pm 2.6$ & 81.1 & \\
\hline G3 & $65.4 \pm 5.2$ & 61.3 & & $63.2 \pm 5.6$ & 60.2 & \\
\hline FIGO stage & & & 0.012 & & & 0.016 \\
\hline I & $79.0 \pm 1.7$ & 87.0 & & $78.2 \pm 1.9$ & 86.2 & \\
\hline ॥ & $68.4 \pm 4.1$ & 68.0 & & $67.9 \pm 4.2$ & 67.9 & \\
\hline Depth of stromal infiltration & & & 0.026 & & & 0.026 \\
\hline$<\mathrm{I} / 2$ & $80.9 \pm 1.9$ & 85.3 & & $80.1 \pm 2.2$ & 84.9 & \\
\hline$\geq \mathrm{I} / 2$ & $66.1 \pm 3.7$ & 70.6 & & $65.6 \pm 3.8$ & 70.1 & \\
\hline Tumor size $(\mathrm{cm})$ & & & 0.029 & & & 0.034 \\
\hline$<4$ & $78.9 \pm 2.2$ & 84.1 & & $78.2 \pm 2.4$ & 83.6 & \\
\hline$\geq 4$ & $66.0 \pm 4.3$ & 67.6 & & $65.4 \pm 4.4$ & 67.0 & \\
\hline Lymph node metastasis & & & $<0.001$ & & & $<0.001$ \\
\hline No & $80.2 \pm 1.9$ & 86.2 & & $79.9 \pm 2.0$ & 86.2 & \\
\hline Yes & $55.4 \pm 5.4$ & 52.0 & & $51.6 \pm 5.9$ & 44.2 & \\
\hline LVSI & & & $<0.001$ & & & $<0.001$ \\
\hline No & $80.2 \pm 1.9$ & 84.9 & & $79.6 \pm 2.0$ & 84.6 & \\
\hline Yes & $57.0 \pm 5.8$ & 57.7 & & $55.9 \pm 5.9$ & 56.7 & \\
\hline HPIP expression status & & & 0.003 & & & 0.002 \\
\hline Low & $82.9 \pm 1.9$ & 90.0 & & $82.6 \pm 2.1$ & 90.8 & \\
\hline High & $66.3 \pm 3.1$ & 68.8 & & $64.9 \pm 3.3$ & 67.4 & \\
\hline
\end{tabular}

Abbreviations: DFS, disease-free survival; FIGO, the Federation of Gynecology and Obstetrics; GI, well differentiated; G2, moderately differentiated; G3, poorly differentiated; LVSI, lymphovascular space invasion; OS, overall survival; SCC, squamous cell carcinoma. 
Table 4 Multivariate survival analysis of II9 patients with cervical cancer

\begin{tabular}{|c|c|c|c|c|c|c|}
\hline \multirow[t]{2}{*}{ Variables } & \multicolumn{3}{|l|}{ OS } & \multicolumn{3}{|l|}{ DFS } \\
\hline & HR & $95 \% \mathrm{Cl}$ & $P$-value & HR & $95 \% \mathrm{CI}$ & $P$-value \\
\hline FIGO stage & 3.397 & I.499-7.698 & 0.003 & 2.927 & I.308-6.552 & 0.009 \\
\hline Lymph node metastasis & 2.650 & $1.09 \mid-6.434$ & 0.031 & 3.036 & $1.221-7.549$ & 0.017 \\
\hline LVSI & 2.738 & I. $145-6.550$ & 0.024 & 2.462 & $1.014-5.975$ & 0.046 \\
\hline HPIP expression status & 3.153 & I. $140-8.723$ & 0.027 & 2.901 & $1.038-8.107$ & 0.042 \\
\hline
\end{tabular}

Abbreviations: DFS, disease-free survival; FIGO, the Federation of Gynecology and Obstetrics; HR, hazard ratio; LVSI, lymphovascular space invasion; OS, overall survival.

knockdown of HPIP could reverse HPIP-induced epithelialmesenchymal transition (EMT) biomarkers, migration, and invasion in U87 and U251 cells. ${ }^{10}$ The HPIP involving in EMT was explored in some cancer cells, such as in A549 cells by inhibiting Smad2 activation, ${ }^{25}$ in thyroid carcinoma cell lines and OAW42 cells by activating the PI3K/AKT pathway, ${ }^{9,26}$ in colorectal cancer cells by the activation of MAPK/ERK1/2 and PI3k/AKT pathways, ${ }^{12}$ and in ovarian cancer cells induced by TGF- $\beta 1 .{ }^{27}$ Recent data also indicated an involvement of HPIP in tumor cell apoptosis, ${ }^{12}$ thereby enhancing cell resistance or survival. Bugide et $\mathrm{al}^{26}$ showed that HPIP expression confers cisplatin resistance to SKOV3 cells and its downregulation decreases the viability of these cells and increases caspase- 3 activation and PARP proteolysis. Another study has inferred that HPIP may be an important modulator of tamoxifen resistance in p53-deficient MCF7 cells through the regulation of AKT-activating proteins. ${ }^{16}$ HPIP sensitized estrogen-receptor-positive MCF-7 cells as well as triple-negative MDA-MB-231 cells to paclitaxel; however, it had no effects on the sensitivity of breast cancer cells to the tubulin polymerization inhibitor, vinblastine, which implying that HPIP may function through microtubule stabilization instead of microtubule catastrophe. ${ }^{28}$ In addition, HPIP has been described to activate some cell cycle regulators that may promote tumor proliferation and progression. ${ }^{7,11,12}$ Furthermore, it revealed that HPIP could

Table 5 Multivariate analysis of the association of lymph node metastasis with HPIP expression status in cervical cancers

\begin{tabular}{llllll}
\hline Variables & B & SE & P-value & OR & $95 \% \mathbf{C l}$ \\
\hline $\begin{array}{l}\text { Age (years) } \\
<43\end{array}$ & & & & & \\
$\quad \geq 43$ & 0.108 & 0.584 & 0.854 & 1.114 & $0.354-3.499$ \\
LVSI & & & & & \\
$\quad$ No & & & & & \\
$\quad$ Yes & 2.004 & 0.546 & $<0.001$ & 7.416 & $2.544-21.620$ \\
HPIP expression status & & & & \\
$\quad$ Low & & & & & \\
$\quad$ High & 2.047 & 0.680 & 0.003 & 7.746 & $2.043-29.365$ \\
\hline
\end{tabular}

Abbreviations: $B$ and SE, the parameter estimator of the association coefficient and its standard error; LVSI, lymphovascular space invasion; OR, odds ratio. mediate specific estrogen receptor signaling in several cancer cells. ${ }^{16,17,29,30}$ These data provide important evidence that elucidates the mechanism by which HPIP expression contributes to carcinogenesis and tumor progression.

\section{Conclusion}

HPIP is overexpressed in a large proportion of CC patients, and high HPIP expression is associated with poor prognosis and progression, especially lymph node metastasis in CC patients. These results suggest that HPIP may be a potential therapeutic target for the treatment of CC.

\section{Acknowledgments}

We thank all the people who had participated in this study.

\section{Disclosure}

The authors report no conflicts of interest in this work.

\section{References}

1. Jemal A, Bray F, Center MM, Ferlay J, Ward E, Forman D. Global cancer statistics. CA Cancer J Clin. 2011;61:69-90.

2. Kodama J, Seki N, Masahiro S, et al. Prognostic factors in stage IB-IIB cervical adenocarcinoma patients treated with radical hysterectomy and pelvic lymphadenectomy. $J$ Surg Oncol. 2010;101:413-417.

3. Noordhuis MG, Fehrmann RS, Wisman GB, et al. Involvement of the TGF-beta and beta-catenin pathways in pelvic lymph node metastasis in early-stage cervical cancer. Clin Cancer Res. 2011;17:1317-1330.

4. Bugide S, David D, Nair A, et al. Hematopoietic PBX-interacting protein (HPIP) is over expressed in breast infiltrative ductal carcinoma and regulates cell adhesion and migration through modulation of focal adhesion dynamics. Oncogene. 2015;34:4601-4612.

5. Abramovich C, Shen WF, Pineault N, et al. Functional cloning and characterization of a novel nonhomeodomain protein that inhibits the binding of PBX1-HOX complexes to DNA. J Biol Chem. 2000;275: 26172-26177.

6. Nishimura K, Hirokawa YS, Mizutani H, Shiraishi T. Reduced heterochromatin protein 1-beta (HP1beta) expression is correlated with increased invasive activity in human melanoma cells. Anticancer Res. 2006;26:4349-4356.

7. Xu X, Jiang C, Wang S, et al. HPIP is upregulated in liver cancer and promotes hepatoma cell proliferation via activation of $\mathrm{G} 2 / \mathrm{M}$ transition. IUBMB Life. 2013;65:873-882.

8. Okada S, Irié T, Tanaka J, et al. Potential role of hematopoietic pre-B-cell leukemia transcription factor-interacting protein in oral carcinogenesis. J Oral Pathol Med. 2015;44:115-125.

9. Wang SC, Chai DS, Chen CB, Wang ZY, Wang L. HPIP promotes thyroid cancer cell growth, migration and EMT through activating PI3K/AKT signaling pathway. Biomed Pharmacother. 2015;75:33-39. 
10. Wang D, Wang L, Zhou Y, Zhao X, Xiong H. The involvement of hematopoietic pre-B cell leukemia transcription factor-interacting protein in regulating epithelial-mesenchymal transition of human spinal glioblastoma. Tumour Biol. 2016;37:5897-5903.

11. Feng Y, Li L, Zhang X, et al. Hematopoietic pre-B cell leukemia transcription factor interacting protein is overexpressed in gastric cancer and promotes gastric cancer cell proliferation, migration, and invasion. Cancer Sci. 2015;106:1313-1322.

12. Feng Y, Xu X, Zhang Y, et al. HPIP is upregulated in colorectal cancer and regulates colorectal cancer cell proliferation, apoptosis and invasion. Sci Rep. 2015;5:9429.

13. Pan J, Qin Y, Zhang M. HPIP promotes non-small cell lung cancer cell proliferation, migration and invasion through regulation of the Sonic hedgehog signaling pathway. Biomed Pharmacother. 2016;77:176-181.

14. Wang Y, Meng F, Liu Y, Chen X. Expression of HPIP in epithelial ovarian carcinoma: a clinicopathological study. Onco Targets Ther. 2016; 10:95-100

15. van Vuurden DG, Aronica E, Hulleman E, et al. Pre-B-cell leukemia homeobox interacting protein 1 is overexpressed in astrocytoma and promotes tumor cell growth and migration. Neuro Oncol. 2014; 16:946-959.

16. Shostak K, Patrascu F, Göktuna SI, et al. MDM2 restrains estrogenmediated AKT activation by promoting TBK1-dependent HPIP degradation. Cell Death Differ. 2014;21:811-824.

17. Wang X, Yang Z, Zhang H, et al. The estrogen receptor-interacting protein HPIP increases estrogen-responsive gene expression through activation of MAPK and AKT. Biochim Biophys Acta. 2008;1783: 1220-1228.

18. Pecorelli S. Revised FIGO staging for carcinoma of the vulva, cervix, and endometrium. Int J Gynaecol Obstet. 2009;105:103-104.

19. Wang Y, Li M, Meng F, Lou G. HPIP expression predicts chemoresistance and poor clinical outcomes in patients with epithelial ovarian cancer. Hum Pathol. 2017;60:114-120.
20. Mai H, Xu X, Mei G, et al. The interplay between HPIP and casein kinase $1 \alpha$ promotes renal cell carcinoma growth and metastasis via activation of mTOR pathway. Oncogenesis. 2016;5:e260.

21. Berek JS, Hacker NF. Practical Gynecologic Oncology. Philadelphia, PA: Lippincott Williams \& Wilkins; 2004.

22. Manavathi B, Acconcia F, Rayala SK, Kumar R. An inherent role of microtubule network in the action of nuclear receptor. Proc Natl Acad Sci US A. 2006;103:15981-15986.

23. Xu X, Fan Z, Kang L, et al. Hepatitis B virus X protein represses miRNA-148a to enhance tumorigenesis. J Clin Invest. 2013;123: 630-645.

24. Chen Y, Zhao R, Zhao Q, Shao Y, Zhang S. Knockdown of HPIP inhibits the proliferation and invasion of head-and-neck squamous cell carcinoma cells by regulating PI3K/Akt signaling pathway. Oncol Res. 2016;24:153-160.

25. Shi S, Zhao J, Wang J, Mi D, Ma Z. HPIP silencing inhibits TGF- $\beta 1$ induced EMT in lung cancer cells. Int J Mol Med. 2017;39:479-483.

26. Bugide S, Gonugunta VK, Penugurti V, Malisetty VL, Vadlamudi RK, Manavathi B. HPIP promotes epithelial-mesenchymal transition and cisplatin resistance in ovarian cancer cells through PI3K/AKT pathway activation. Cell Oncol (Dordr). 2017;40:133-144.

27. Zhang GY, Liu AH, Li GM, Wang JR. HPIP silencing prevents epithelial-mesenchymal transition induced by TGF- $\beta 1$ in human ovarian cancer cells. Oncol Res. 2016;24:33-39.

28. Yu B, Tian X, Zhang L, Feng R. Hematopoietic PBX-interaction protein promotes breast cancer sensitivity to paclitaxel through a microtubuledependent mechanism. DNA Cell Biol. 2016;35:740-745.

29. Selina AK, Murat K, Emre K, Ismail M, Bunyami U, Cemal G. The relationship between estrogen receptors and microtubule dynamics in post-menopausal rat brain. Acta Histochem. 2015;117:747-751.

30. Yu YH, Siao FP, Hsu LC, Yen PH. TEX11 modulated germ cell proliferation by competing with estrogen receptor $\beta$ for the binding to HPIP. Mol Endocrinol. 2012;26:630-642.
OncoTargets and Therapy

\section{Publish your work in this journal}

OncoTargets and Therapy is an international, peer-reviewed, open access journal focusing on the pathological basis of all cancers, potential targets for therapy and treatment protocols employed to improve the management of cancer patients. The journal also focuses on the impact of management programs and new therapeutic agents and protocols on

\section{Dovepress}

patient perspectives such as quality of life, adherence and satisfaction. The manuscript management system is completely online and includes a very quick and fair peer-review system, which is all easy to use. Visit http://www.dovepress.com/testimonials.php to read real quotes from published authors. 